\title{
Abrupt aggravation of atrioventricular block and syncope in hypertrophic cardiomyopathy
}

\author{
Masamichi Tamura, Kenji Harada, Tadahiko Ito, Masamichi Enoki, Goro Takada
}

\begin{abstract}
A 10 year old girl with hypertrophic cardiomyopathy (HCM) developed high grade atrioventricular (A-V) block unexpectedly, which instantly led to syncope; she required a permanent pacemaker. High grade A-V block, a rare complication of HCM, relates closely to syncope or sudden death in this disease and if progressive the use of cardiac pacing should be considered without delay.

(Arch Dis Child 1995; 73: 536-537)
\end{abstract}

Keywords: hypertrophic cardiomyopathy, atrioventricular block, syncope.

Although the prevalence of conduction disease in hypertrophic cardiomyopathy (HCM) is by no means unusual, reports of high grade or complete atrioventricular (A-V) block in HCM are rare, ${ }^{1}$ particularly in children. ${ }^{2}$ We report here a 10 year old girl with HCM who spontaneously developed high grade $\mathrm{A}-\mathrm{V}$ block, which instantly led to syncope. It seems that a rapid progression of $\mathrm{A}-\mathrm{V}$ block is closely related to syncope and sudden death in a child with HCM.

\section{Case report}

A 10 year old girl was referred to us for evaluation. HCM had been diagnosed in our hospital at 5 years of age by echocardiography (fig 1) and cardiac catheterisation, and she had been receiving a $\beta$ receptor blocker and an angiotensin converting enzyme inhibitor since 5 and 9 years of age, respectively. There was no family history of HCM or sudden death. On the morning of admission, she felt a heavy feeling in her chest but went to school as usual. As the symptom became worse, she was sent to our hospital. Her heart rhythm was irregular and her blood pressure was $100 / 70 \mathrm{~mm} \mathrm{Hg}$. Chest radiography showed an enlarged heart with a cardiothoracic ratio of $0 \cdot 65$. An electrocardiogram (ECG) revealed second degree $\mathrm{A}-\mathrm{V}$ block with 3:2 conduction (fig 2B). An echocardiogram demonstrated poor left ventricular activity but no pericardial effusion. Shortly after these examinations, she developed high grade A-V block (fig 2C) and lost consciousness almost instantly. A temporary ventricular pacemaker was immediately inserted and she regained consciousness. Atropine was ineffective. A subsequent echocardiogram showed an improvement of left ventricular activity. Permanent pacemaker implantation using dual chamber pacing was performed four days after admission and resulted in a remarkable improvement. She has been asymptomatic during a follow up period of two months, but high grade $\mathrm{A}-\mathrm{V}$ block has remained unchanged.

Myocarditis was excluded as no significant increase in the virus antibody titres studied was detected. There was no significant increase in antistreptolysin-O and no evidence of infectious endocarditis was found. Cardiac catheterisation performed 11 months before the admission showed normal coronary arteries and features of a midventricular obstructive HCM with a pressure gradient of $28 \mathrm{~mm} \mathrm{Hg}$. At that time, no arrhythmia was observed on an ambulatory ECG or elicited by an exercise stress test. An ECG recorded two months before admission showed regular sinus rhythm of 63 beats/minute, 0 degrees of mean frontal plane $Q R S$ axis, 0.16 second of $P Q$ interval, and $0 \cdot 16$ second of abnormally wide QRS duration (fig 2A).

\section{Discussion}

We describe here a case of HCM with spontaneous development of high grade $\mathrm{A}-\mathrm{V}$ block, which is a very rare complication

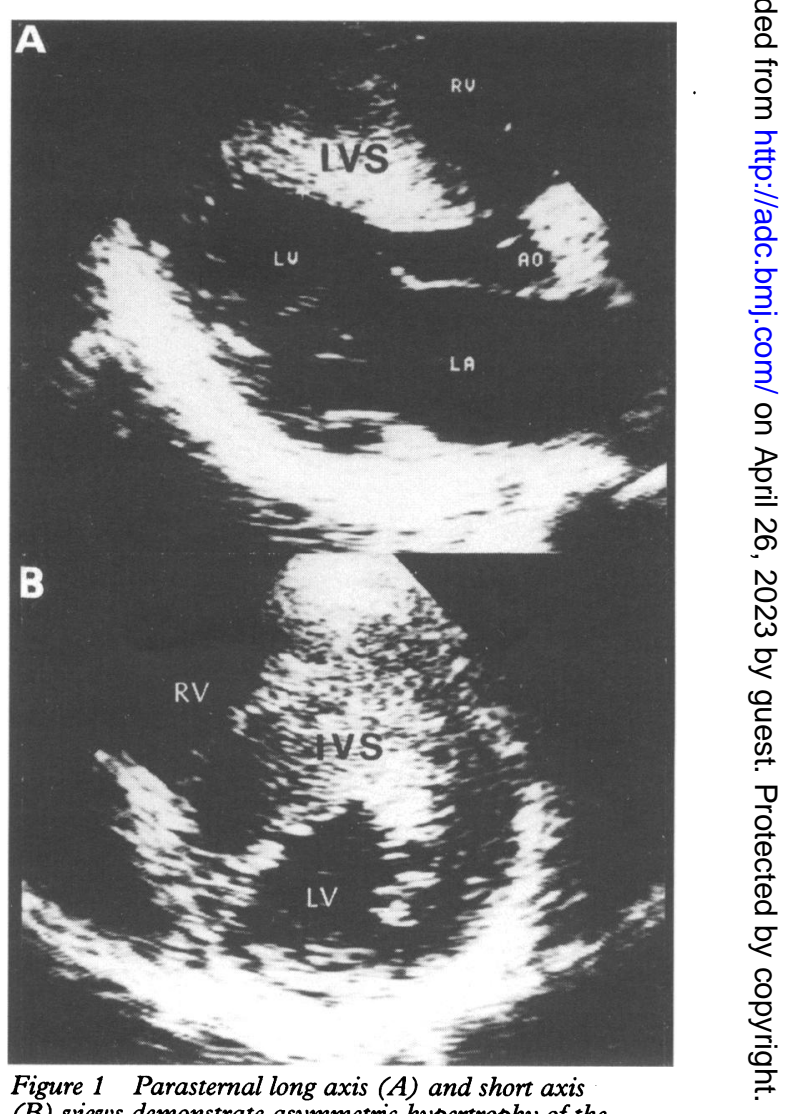
(B) views demonstrate asymmetric hypertrophy of the ventricular septum. $A O$, aorta; IVS, interventricular septum; $L A$, left atrium; $L V$, left ventricle; $R V$, right ventricle. 

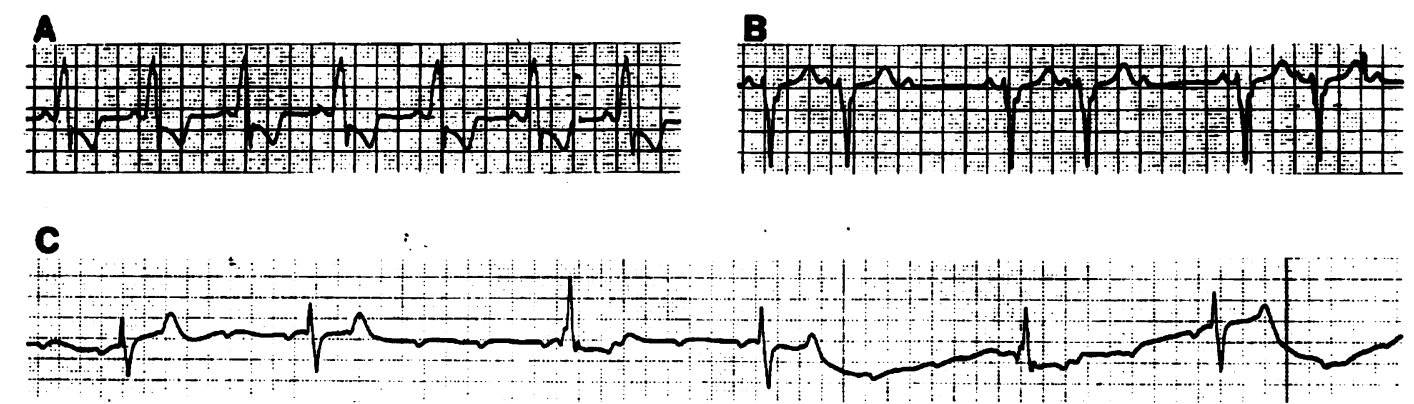

Figure 2 Electrocardiograms at rest. (A) Regular sinus rhythm at two months before admission: (B) second degree A-V block with 3:2 conduction on admission; and $(C)$ high grade $A$-V block during syncope.

especially in children. To our knowledge, there is only one case report of a child in the literature. ${ }^{2}$ As the diagnosis of HCM in that case was not definitely established, our patient is probably the first child with HCM and acquired high grade $\mathrm{A}-\mathrm{V}$ block. A variety of systemic disorders are known to cause acquired $\mathrm{A}-\mathrm{V}$ block. In adult HCM with advanced conduction disease, changes including interstitial fibrosis or myocardial necrosis were histopathologically observed in the conduction system including the sinus and $A-V$ nodes, and the bundle of His. ${ }^{3}$ Some authors referred to the relation between HCM with acquired high grade $\mathrm{A}-\mathrm{V}$ block and such changes. $^{34}$ Accordingly, we speculate that spontaneous development of high grade $A-V$ block may be caused by degenerative changes, even in children, if they are progressive and severe enough. Our patient rapidly changed from second degree $\mathrm{A}-\mathrm{V}$ block to a high grade one, and developed severe syncope in a very short time. If the timing of the temporary cardiac pacing had been too late, our patient might have died. This clinical course is similar to the case reported by Chmielewski et al. ${ }^{5} \mathrm{It}$ has been reported that the fatality rate for HCM is higher in children and young adults, and most patients die suddenly and unexpectedly. ${ }^{6}$ In addition, definite histological changes in the A-V nodes and the bundle of His have been observed in children with HCM who died suddenly. ${ }^{7}$ If A-V block occurs and progresses rapidly to high grade block and then to severe syncope, as in our case, death will be inevitable. It is possible that the sudden appearance of high grade $\mathrm{A}-\mathrm{V}$ block is a more frequent cause of sudden death in children with HCM than previously suspected. To prevent syncope and sudden death is one of the major aims of treatment in HCM. We do not know exactly why the occurrence of high grade A-V block in HCM is apparently rare, but it does not occur by chance and can be hard to predict. Our case suggests that a bradycardic arrhythmia such as A-V block has a definite possibility of causing syncope and sudden death in children with HCM. Therefore, awareness of this conduction defect is important and the use of cardiac pacing should be considered, even in second degree $\mathrm{A}-\mathrm{V}$ block, if it is progressive.

1 Przybojewski JZ, van der Walt JJ, Ellis GC, Tiedt FA. Hypertrophic cardiomyopathy complicated by complete heart block. Case report and review of the literature. $S$ Afr Med f 1984; 66: 847-55.

2 Luisada AA. Sub-aortic muscular stenosis and complete heart block in an adolescent. Pediatric-surgical-cardiac conference case presentation. Chicago Medical School Quarterly 1965; 25: 169-75.

3 Gavrilescu S, Gavrilescu M, Streian C, Luca C. Hypertrophic obstructive cardiomyopathy associated with complete heart block. Pathologic correlations in a case studied with His bundle electrography. Acta Cardiol 1974; 29: 241-9.

4 Khair GZ, Bamrah VS. Syncope in hypertrophic cardiomyopathy. I. Association with atrioventricular block Am Heart f 1985; 110: 1081-3

5 Chmielewski CA, Riley RS, Mahendran A, Most AS. Complete heart block as a cause of syncope in asymmetric septal hypertrophy. Am Heart $\mathcal{F}$ 1977; 93: 91-3.

6 McKenna WJ, Franklin RC, Nihoyannopoulos P, Robinson KC, Deanfield JE. Arrhythmia and prognosis in infants, children and adolescents with hypertrophic cardiomyopathy. $\mathcal{F}$ Am Coll Cardiol 1988; 11: 147-53.

7 James TN, Marshall TK De subitaneis mortibus. XII. Asymmetrical hypertrophy of the heart. Circulation 1975; 51: $1149-66$. 